\title{
Rethinking Utility Theory
}

\author{
F. THOMAS JUSTER' \\ University of Michigan
}

\section{INTRODUCTION}

Economists have had a long-standing concern with understanding and modeling the behavior of consumers, both in the narrow sense of their behavior as buyers of goods and services in product markets and as suppliers of services in labor markets, and in the broader sense of their collective purchases of public goods-schools and roads, air and water quality, national security, etc. Analysis of these issue has been cast as a constrained optimization problem: Consumers are perceived as choosing a particular bundle of goods and services, or a combination of work and leisure hours, or a set of taxes and public goods, that represents the optimum mix subject to the constraints of income and prices. Optimum simply means that no change can improve matters, and what is being optimized is utility or satisfaction.

This paper provides a brief history of the development of utility theory, and suggests a reconceptualization of the basic sources of utility. The new formulation extends the range of interesting and important phenomena encompassed by the theory, reexamines the role of goods and services in producing utility, and simplifies the conceptual structure-at the cost of complicating the measurement problem as well as the analytic properties of the systcm. Some recent data reflecting the new conceptual structure are examined, and we note some implications of the theory and data for both scientific and policy issues.

Direct all correspondence to: F. Thomas Juster, Institute for Social Research, Box 1248. University of Michigan, Ann Arbor, MI 48106.

The Journal of Behavioral Economics, Volume 19, Number 2, pages 155-179

Copyright 1990 by JAI Press Inc.

All rights of reproduction in any form reserved.

ISSN 0090-5720 


\section{GOODS}

The original concept of utility, developed principally by the moral philosopher Jeremy Bentham ${ }^{(6)}$ in the late eighteenth century and formally integrated into the analysis of economic problems by Jevons, Menger and Walras in the 1870 s, was that is represented a cardinally measurable psychological flow of satisfactions attached to goods and services purchased in the market-consuming a mutton chop yields $x$ utils of satisfaction or pleasure. ${ }^{2}$ The utility function for the consumption of good $x$ was presumed to be independent of the function for good $y$, and consumers were visualized as equating the utility of the last unit of each good purchased (the marginal utility) with its price. Thus the last dollar spent on housing or clothes or food yielded the same amount of satisfaction, since otherwise consumers could increase total utility by switching a unit of expenditure from one product to another. And marginal utility was a declining function of the amount of each good consumed: otherwise, consumers could move away from the "equal utility on the last unit of expenditure" position by switching a unit from some good to one whose utility was rising, thus increasing total utility. Eventually, unless marginal utility declined, consumers would wind up buying one commodity only - the one whose marginal utility was rising-which is counter to common observation. ${ }^{3}$

The idea of cardinally measurable utility, independence of the utility functions for different goods, and declining marginal utility gradually eroded as economists began to recognize that not only was there little scientific underpinning to the notion that consumers could make precise assessments of the psychological satisfactions associated with utility (or that psychologists had satisfactory theories that could explain utility), but more importantly, that the assumption of cardinally measurable utility was not essential to an explanation of economic behavior. Thus utility as a quantitative measure of psychological satisfaction began to be replaced by the simpler notion that consumers (for whatever reason) had preferences for one combination of goods over another, and that these preferences (or preference orderings) could be revealed by observing the choices that consumers made in the marketplace. It was still true that the term utility was often used to describe what consumers were trying to maximize in making choices, but it was only necessary to assume that consumers could make consistent choices-if A was preferred to B and B to C, consumers would necessarily prefer A to C.

To replace the analytic apparatus that involved equality in the ratios of marginal utility to price, economists developed the notion of a generalized utility function (the utility functions for different goods weren't necessarily independent) and of an indifference surface: Consumers were thought of as judging that various combinations of different products (more of one and 
less of the other) were of equivalent utility, or that one combination produced more (or less) utility than another. The equilibrium conditions became ones where the marginal rates of substitution of one commodity for another (if I give up a pound of beef, how many quarts of beer are needed to make me equally welloff) had to be equal to the ratios of their prices (Edgeworth, ${ }^{(15)}$ Pareto, ${ }^{(52.63)}$ Slutsky, ${ }^{\left({ }^{(3)}\right)}$ Fisher ${ }^{(18)}$ Hicks \& Allen ${ }^{(24)}$ and Samuelson $\left.{ }^{(11)}\right){ }^{4}$

The utility function implied by the preferences ordering notion had utility as a function of the consumption of goods and services as reflected by Equation 1,5 with total utility constrained by the total amount of goods and services that could be purchased with the consumer's money income (Equation 1.1).

$$
U=u\left(x_{1}, x_{2}, \ldots x_{n}\right)
$$

where $U$ is utility and the $x_{\mathrm{i}}$ are goods and services (service flows in the case of durable goods).

$$
\sum_{i=1}^{n} \quad P_{i} x_{i}=I=W+V
$$

where the $p_{i}$ 's are prices, $I$ is money income, $W$ is earnings of household members, and $V$ is nonwage income of the household.

\section{GOODS AND LEISURE}

The idea that utility was constrained by total money income, and that the utility maximization problem consisted of deciding which commodities to consume, given their prices and the household's income, was significantly broadened when it became recognized that money income itself was a choice variable, and that consumers were really maximizing the utility derived jointly from a combination of goods and leisure (Robbins, (57) Hicks(22)). In effect, in earlier discussions, money income had been implicitly treated as an exogenous variable, essentially given to the consumer unit. ${ }^{4}$ In later discussion, wage rates were the exogenous variable and money income was endogenously determined by the combination of the wage rate and the choice variable of work hours. ${ }^{7}$ Thus the utility function looked like Equation 2, in which consumers first had to make a choice about how much income to earn and how much leisure to consume, then decide on the 
combination of goods and services to purchase with their money income. The constraints were that total money income fixed the total value of consumption (including future consumption or saving), and that total available time fixed the sum of labor market hours and leisure hours-with leisure defined to include all activities except work for pay in the market.

$$
U=u(l, L)
$$

where $I$ is total consumption (including saving for future consumption), and $L$ is leisure time.

$$
\sum p_{i} x_{i}=I=w T_{m}+V
$$

where $w$ is the wage rate and $T_{m}$ is labor market hours, and

$$
T=T_{m}+L
$$

It is worth noting that in these simple models, the utility function contains one item that reflects market choices (the consumption of goods and services) and a second that reflect nonmarket activities (the consumption of leisure). Thus the model has consumers supplying labor to the market up to the point where the income produced by the last unit of labor produces just enough utility to overcome the distaste for work. In effect, the model treats income as producing positive utility, leisure activities as producing positive utility, but work activity as producing negative utility, at least at the margin of choice. ${ }^{8}$

Another interesting feature of these utility maximization models is that the earlier switch from cardinally measurable utility to ordinally measured preferences, while perhaps reflecting a more realistic assessment of the way consumers actually made choices, ${ }^{9}$ also significantly modified the way in which economists thought about intertemporal (i.e., multiperiod) utility maximization. In the early (Bentham, etc.) theoretical structure, intertemporal utility maximization was accomplished by including in the current period utility function a particular representation of future utility-the current pleasure obtained by contemplating (savoring) future consumption (Loewenstein, ${ }^{(42)}$ ). In that model, consumers could make choices about giving up current consumption to get consumption in the future, but all utility maximization took place during the current period: Future consumption yielded utility only in terms of the current satisfaction obtained from anticipation of a future event. 
When preference ordering replaced marginal utility, intertemporal utility maximization took the form of consumers optimizing over time by equating (at the margin) the flow of satisfaction yielded by current consumption with the future flow of satisfaction yielded by future consumption, not by equating the satisfaction from present consumption with the current satisfaction from savoring the prospect of future consumption. Thus economists thought of future consumption as yielding utility only when it actually took place, and since future satisfactions were generally thought to be worth less than current ones, they had to be discounted to reflect their futurity."

\section{"COMMODITIES" AND LEISURE}

The notion that goods purchased in the market and leisure were the right way to think about utility functions was significantly modified by the household production framework introduced by Becker in the middle 1960s (Becker, ${ }^{(5)}$ Mincer ${ }^{(47)}$ Michael \& Becker ${ }^{(45)}$ Nerlove,,$\left.{ }^{(50)}\right)$." Becker extended the notion of productive activity to include the proposition that households used elements of their own time as inputs to the production process, along with goods purchased in the market, to produce outputs ("commodities") that were the ultimate objects of utility. Thus, time could be allocated directly to the market, where it yielded income and thus command over goods and services, it could be used within the household to produce commodities, or it could be used as leisure (treated as a commodity in the Becker framework). The ultimate sources of utility, in this model, were commodities produced within the household-meals, children of certain quantity and quality, going to plays, etc., which typically involved the joint inputs of market-purchased goods and services plus the household's own time.

These "commodities" could be thought of as having shadow prices-the cost of the market-produced input plus the valuc (wage rate) of the time of household members. Thus, certain types of commodities were expensive to produce for certain types of households - child quantity and quality, for example, would be an expensive commodity to produce for households with highly-educated mothers, since the opportunity cost of their market time would be relatively high. And given family income, adults with high (actual or potential) wage rates would tend to stay away from time-intensive activities in favor of goods-intensive ones (e.g., they would play squash rather than golf), while low wage-rate adults would favor time-intensive over goods-intensive activities (e.g., they would serve as community volunteers).

In this model, it is still true that household well-being was a joint function of consumption and leisure. However, instead of the relevant goods being 
only those produced in the market and reflected in, say, the Gross National Product, consumption was broadened to include a range of outputs that reflected nonmarket production as well as market production. Thus, a wider range of goods and services was included in the notion of commodities. The formal structure is spelled out in Equations 3 to 3.3.

$$
U=u\left(Z_{1}, Z_{2}, \ldots Z_{n}\right)
$$

where the $Z_{i}$ are commodities produced within the household with market goods $x_{i}$ and the time of household members $t_{i}$.

$$
Z_{i}=z_{i}\left(x_{i}, t_{i}, E\right)
$$

which is the production function constraint on the $Z_{i}$, given the $x_{i}$, the $t_{i}$ and $E$ (the household production technology).

$$
T=T_{m}+\sum_{i=1}^{n} t_{i}
$$

where $T_{m}$ is time spent in the labor market at paid work and the $t_{i}$ represent all other time uses.

$$
S=w T+V=\sum_{i=1}^{n} w t_{i}+p_{i} x_{i}
$$

where $S$ is the "full income" of the household, $w$ is the wage rate, and $V$ is the nonlabor income.

A major difficulty with this model was pointed out by Pollack and Wachter ${ }^{(5)}$ in 1975 . They argued that the shadow prices in the household production model were indeterminate except under special conditions that were unlikely to hold. The household production function in which the time of household members is used to produce "commodities" specifies the wage rate as the cost of nonmarket production time. That specification assumes that consumers do not have any preference for the way in which their time is spent, quite apart from any preferences they may have for the output resulting from those inputs of time. Since the outputs and time use prefer- 
ences are joint products of activity, Pollack and Wachter concluded that the system could not be uniquely solved for shadow prices, absent information about the intrinsic preferences of household members for time spent in various household production tasks.

\section{WHERE DO WE GO FROM HERE?}

These developments can be thought of as reflecting a broadening of utility theory in terms of the potential sources of human satisfaction. The focus on goods found in the eighteenth and nineteenth century writers came to include goods and leisure in the early twentieth century, and to include nonmarket "commodities" and leisure during the last few decades. ${ }^{12}$ At the same time, there was a gradual but eventually complete stripping away of any notion that the theory had (or needed) any cardinally measurable utility content. It required only preference orderings that could be inferred from observed choices.

While the ordinalist view of utility is clearly the dominant strain of thinking among economists, the idea of direct (cardinal) measurement of utility has always lurked uneasily in the background even when the more vocal (rigorous?) proponents of ordinality thought that it had been stamped out as unnecessary (on the Occam's Razor principle) for models of consumer behavior. Even Hicks, who along with Allen "slit the throat of diminishing marginal utility" (p. 4), came to think that (cardinally measurable) marginal utility was a better description of what consumers actually did than the idea of their equating marginal rates of substitution with price ratios. ${ }^{(23)}$ Stigler and Becker, hardly cardinalist heretics, revived the notion of households as mini-factories producing a stream of utility $y^{(67)}$ - just like real factories producing a stream of (cardinally measurable) profits? And Pollack and Wachter suggested that the shadow prices for "commodities" in the household production framework could not be determined because these commodity prices were not exogenous to any household that had (cardinally measurable?) preferences over their use of time in household production.

This paper argues for the importance of direct (cardinal) measurement of utility, and outlines a conceptual framework in which such measurements play a central role. First, it is argued that a properly conceptualized utility theory implics mcasurcments that cannot be inferred from behavior but must be obtained directly from consumers, and that this conceptualization can help to predict behavior that is not otherwise understandable. Second, the measurements suggested by this conceptualization relate directly to consumer well-being. Understanding what determines well-being, and how it is distributed among the population, is important in its own right independently of any behavioral implications. 


\section{UTILITY, ACTIVITIES, AND GOODS}

A little reflection (introspection, actually) on the nature of production and consumption, and on the characteristics of various sources of utility or satisfaction, provides some helpful clues about the utility maximization problem and how it might best be reformulated. Consumers do not generally get utility directly from any of the goods and services purchased in the market and presumed to enter the utility function. The purchase of food, clothing, housing, automobiles, or theatre tickets does not do much for one's utility, nor does cooking food, cleaning and straightening the house, using an automobile to get from home to the theater, or disciplining a child. But utility is obtained directly from activities like eating meals (where a level of utility depends partly on the quality of food), seeing a play (where the level of utility depends partly on the quality of the acting), entertaining friends in one's home (where the level of utility depends partly on the quality of the home and its furnishings), taking one's child on an outing, etc.

This illustrative comments suggest some general principles about the relation between goods, activities, and utility.

1. Utility flows arc always derived from activities (cating, socializing, playing tennis, seeing a play, etc.).

2. The amount of utility derived from an activity depends partly on the amount of goods associated with it (quality and variety of food, clothing, housing, sporting equipment, etc.).

3. Some of the goods that influence the utility from activities are flows consumed during the activity (food, theater tickets), but many are capital stocks that yield service flows (housing, clothes, cars, TV sets).

As illustrations, one presumably derives more utility from listening to a high quality recording of Beethoven's Fifth Symphony played on an equally high-quality sound system than from listening to the same notes played over a transistor radio, and the satisfaction from that experience is presumably influenced by whether one does the listening in a poorly heated room without much furniture than if it is done in the comfortable and wellappointed living room or den of an equally comfortable and well-appointed dwelling. The utility derived from eating meals presumably depends on the quality and variety of the food that goes into the meal. And so on.

Are there aspects of utility that are not associated with activities of one kind or another? The answer seems to be yes. I do not necessarily have to be driving a Porsche, and thus obtaining satisfaction from the process, in order to derive utility from owning one. I do not necessarily have to engage in conversation or interaction with my wife or children to derive satisfaction from the existence of a strong family relationship. I am likely to be more 
pleased about life generally if I think that the society I live in is characterized by equity in the tax laws, in the administration of justice, in the distribution of income, and by equality of opportunity. And so on.

Can we systematize these illustrative notions about utility, how it is produced, and how it might be assessed? Perhaps. A system with these general characteristics has been outlined, at least in embryonic form by Juster, Courant, and Dow. ${ }^{(31.32 .33)}$ The basic idea spelled out in these papers is that society can be thought of as having only two fundamental resources - the stock of wealth inherited from past productive activity and not consumed, and the available time of all members of society. Wealth is used here in a substantially broader sense than the tangible capital stock used in the production of goods and services in the market. While such wealth is clearly part of the total, a broader notion of wealth incorporates human capital assets (skills, health status), stocks of organizational capital (networks of associations within business organizations, within families, within neighborhoods, etc.), stocks of sociopolitical assets (the judicial system, the representational system, etc.), stocks of environmental assets (natural resource endowments, air and water quality), and stocks of abstract knowledge not embodied in existing capital equipment. Thus the set of stocks relevant to the generation of utility include any asset that conditions either the efficiency of, or the satisfactions associated with, various time uses.

In this model, time can be used as in the household production literature-for the production of market goods and services (the $x$ 's in Equations 1 and 2), for the production of household outputs (the $Z$ 's in Equation 3), for household maintenance activities (generally ignored in the literature), or for leisure activities (also Z's in Equation 3). The general idea embodied in this model of utility is that the production of goods and services in the market is determined by capital stocks and labor market time, that market goods, nonmarket time and stocks of capital affect the efficiency with which households can produce commodities, and that flows of market goods and services and of household produced commodities, along with capital stocks, condition the satisfactions (let us call them process benefits) associated with activities.

One of the interesting features of this way of thinking about the utility function is that all of the tangible and intangible outputs of various production processes, whether they take place in the market or within households, represent inputs into the intrinsic satisfactions (process benefits) associated with one or another activity, or else they represent goods and services that add to the stock of wealth available for the production of future satisfactions. But what is not so obvious is that the flows of all tangible or intangible products, which represent the extrinsic outputs from productive activity, 
disappear from the utility function, either because they are fully represented by the process benefits obtained from one or another activity or because they add to capital stocks.

An illustration may make the point clearer. Labor market time and capital stocks go into the production of food available in grocery stores, the time of household members in conjunction with market-produced food goes into the production of meals, and meals go into the production of two further types of output - the process benefits from eating and any change in health status associated with nourishment. Should we count the process benefits from eating along with the nonmarket time and household stocks that transform raw food into meals, or the labor market time and business capital stocks that go into the production of raw food? The answer seems to be no, anymore than we would include in the GNP the automobile that was eventually purchased by consumers, the component parts like fenders and wheels that were produced by the automobile assembly plant, the steel that went into the fenders and the rubber that went into the tires, and the iron ore that went into the steel. That would clearly by double-counting. Once we count the car, we ought not to count the components as well. The solution, standard in National Income accounting, is to exclude from net output any purchased product that represents a production input, and to count only the value-added at each stage of production.

But that is no more double-counting than adding up the process benefits from eating along with the time and resources going into the transformations of food into meals or the time and resources going into the production of food. If we have properly measured the process benefits associated with eating meals, we have also measured the contribution to utility of the intermediate tangible outcomes (meals and raw food) as well. But what we have not measured are any process benefits associated with the various production processes, along with the fact that eating meals is not only a source of current utility but may also be a source of future utility because it has a possible impact on health status. In short, the flow of process benefit is the value-added equivalent of the household production function.

Gcncralizing this proposition across all production activities leads to the conclusion that accurate measurement of the process benefits associated with all activities fully comprehends the sources of current utility from goods and commodities, and adding to that any current or future satisfaction associated with the various capital stocks in the system fully comprehends all potential sources of utility.

Not only is it true that all the tangible product flows of society enter the utility function by conditioning the process benefits from some activity, but it is also true that every activity contains an element of process benefits. Economists have typically thought of process benefits as largely associated 
with leisure. After all, the conventional wisdom is that consumers work in order to earn income so that they can enjoy leisure. But productive activity, both within the market and the home, also produces a flow of process benefits (which may be negative, if one thinks of utility of having a true zero point). The only difference between production activities and consumption activities is that production activities have both a flow of extrinsic products as well as a flow of process benefits, while many leisure activities can be thought of as having only the latter. ${ }^{13}$

Formally, the utility structure implied by this view of the world is represented by Equations 4 to 4.3 .

$$
U=u\left(x_{i}, Z_{i}, t_{i}, K_{o}, K_{1}\right)
$$

where the $x_{i}$ are market-produced goods and services, the $Z_{i}$ are household produced commodities, the $t_{i}$ are time uses, $K_{o}$ is the household's initial capital stock, and $K_{1}$ is the end of period capital stock.

Since the $x_{i}$ are all inputs into the $Z_{i}$, and the $Z_{i}$ are all inputs into the process benefits from some time use, all that is left in the utility function are the process benefits from all time uses, $P B_{i}$, the current period satisfactions from those capital stocks that yield utility directly and independently of any time use, $K_{\mathrm{o}}{ }^{*}$, and the contribution to future utility represented by the endof-period capital stock $K_{1}$. Thus:

$$
U=u\left(P B_{i}, K_{\mathrm{o}}{ }^{*}, K_{1}\right)
$$

subject to the constraints of beginning period capital stock and total available time. ${ }^{14}$

$$
K_{0}, K_{\mathrm{o}}{ }^{*}
$$

given

$$
T=\sum_{i=1}^{n} t_{i}
$$

The notion that activities are the basic source of utility turns out to have clearly identifiable historical roots. As Loewenstein ${ }^{(45)}$ notes in his literature survey, Edgeworth in Mathematical Psychics conceived of the individual as 
an enormously complex machine whose purpose was to convert inputs such as time and food and consumption goods into pleasure, and the same theme was echoed several decades later by Irving Fisher, who wrote:

\begin{abstract}
These and other illustrations will show that, if we include the body as a transforming instrument, while we must credit with their respective service all these outside agencies, such as food, clothing, dwelling, furniture, ornaments, and other articles, which, as it were, bombard a man's sensory system, we must also at the same time debit the body with these same items. In this case, the only surviving credit items after these equal debits and credits are cancelled are the resulting satisfactions in the human mind. In other words; in order that the external would should become effective to man, the human body must be considered as the last transforming instrument. Just as there is a gradual transformation of services through the farm, flour mill, and bakery, so there is a gradual transformation within the human body itself. It is a sort of factory, the products of which are the only uncancelled income of the consumer (Fisher, ${ }^{\left(1{ }^{16}\right)}$ p. 167)..$^{16}$
\end{abstract}

Assume for the moment that it is logically consistent to think about utility and well-being as fully represented by the flow of process benefits associated with a comprehensive set of activities, in addition to the current and future satisfactions represented by various kinds of capital stock. Does that framework tell us anything useful? More importantly, is there any way in which one could imagine implementing the idea empirically?

\title{
DIRECT MEASUREMENTS OF UTILITY
}

The division of utility into a component associated with time uses and another component associated with capital stocks of one kind or another is a useful starting point. We can clearly measure time uses, at least in principle. Whether we can measure the utility associated with time uses is another question. In principle, one could imagine measurements taking the form of attaching a perfectly calibrated "utility meter" to the appropriate part of a consumer's brain, and monitoring the level of utility associated with activity as consumers proceed to do various things throughout the day and the year. That procedure depends, of course, on the existence of a utility meter that uniquely maps actual utility; otherwise, it would be open to the objection that some characteristic of brain cell activity was being monitored, without it necessarily having anything to do with utility. ${ }^{16}$

Assume that problem away for the moment. It is obviously possible to measure utility in the population at large either by continuous monitoring of the utility flows associated with activities, or by sampling utility at randomly selected intervals of time throughout the day or the year. That procedure would not get around any of the problems associated with interpersonal utility comparisons, unless one is willing to assume that the brain monitor utilized an exactly equivalent utility metrics across all individuals. But the 
answer seems to be that, provided one can measure activities and measure the utilities associated with activities, the part of utility associated with activities could in principle be analyzed.

The part of utility associated with capital stocks is equally problematic. It is clear enough that this is a potentially important component of utility, and it may be that the utility involved in the existence or ownership of capital stocks is harder to capture because it has the character of a pervasive sense of satisfaction arising from some state of the world rather than being associated with some process or activity. But one could easily imagine a survey that asked consumers about the state of their marriage, the state of their durable goods, their perception of the state of the world, their satisfaction with the income distribution, etc.

In fact, both types of measurement actually exist. As a by-product of a national survey of time use among American households, motivated principally by a desire to understand the character of nonmarket activities in households, we obtained not only measurements of actual time uses among a probability sample of U.S. consumers, but also a measure of the process benefits associated with a subset of activities. The data do not come very close to representing a "utility meter" reading of the sort described, and they do not represent the instantaneous satisfaction obtained from momentary activities. Rather, they represent statements about the average amount of satisfaction from activities with descriptive labels like watching television, going to the movies, playing sports or games, cleaning the house, working at your job, taking care of children, etc. Thus, they are not quite mapped into instantaneous utilities associated with current activities.

As to the capital stocks, sociologists, social psychologists (and even a few economists) have in recent decades developed a keen interest in what are called "Quality of Life" measurements. On inspection, these turn out to be largely measures of satisfaction with various kinds of "capital stocks," defined broadly as above, although some of them are closer to satisfaction with activities than with capital stocks. But reported satisfaction with marriage, friendships, financial security, durable good stocks, etc., have been examined in a series of studies (Campbell, Converse and Rogers, ${ }^{\left({ }^{(1)}\right)}$ Bradburn, ${ }^{(8)}$ Cantril \& Roll, ${ }^{(11)}$ Andrews and Withey, ${ }^{(1)}$ and Juster, Courant and Dow, ${ }^{(31)} \cdot{ }^{17}$

Whether this way of thinking about well-being is useful or not has to be determined in the usual way. Those who think it is useful produce analyses based on it, and those analyses either influence the way other economists think about related problems or they do not. But some interesting insights can be obtained from the existing measurement. We focus on the activity measurements, and on the intrinsic satisfactions associated with them. Measurement of the capital stock utility flows is a different story, and are ignored in this paper. 
As indicated, relatively crude data of this sort were obtained in the mid-1970s and in the early 1980s, as part of national studies of time allocation among American households. Twenty-four hour time diary data were obtained from a random sample of American adults. Respondents were also asked to rate a comprehensive list of activities on a 10 to 0 scale, with 10 characterizing an activity from which the respondent derived a great deal of satisfaction (enjoyment was the actual term), 0 an activity associated with a good deal of distaste (dislike was the actual term), and 5 an activity to which respondents were indifferent-don't care about it one way or the other was the description. On a cardinal utility scale, 5 can be thought of as equivalent to a zero point, with higher numbers being positive and lower numbers negative.

The basic data are displayed in Table 1 , ordered by the mean population values of the process benefit scorcs in the mid-1970s survey. We show activity categories, mean process benefits in 1975 and 1982, the "reliability" proportion (described below), and the mean amount of time spent on the

Table 1: Basic Process Benefit Data Reported by Respondents

\begin{tabular}{|c|c|c|c|c|c|}
\hline \multirow[b]{2}{*}{ Activity } & \multirow[b]{2}{*}{$N$} & \multicolumn{2}{|c|}{$\begin{array}{c}\text { Mean Process } \\
\text { Benefit Score }\end{array}$} & \multirow{2}{*}{$\begin{array}{l}\text { "Reliability" } \\
\text { Proportion }\end{array}$} & \multirow{2}{*}{$\begin{array}{c}\text { Time Spent } \\
\text { in } 1975 \\
\text { (hours/day) }\end{array}$} \\
\hline & & 1975 & 1982 & & \\
\hline Talking with children & 312 & 9.16 & 8.98 & .80 & .07 \\
\hline Care of children & 312 & 8.87 & 8.74 & .82 & .50 \\
\hline Trips with children & 311 & 8.87 & 8.72 & .74 & .03 \\
\hline Games with children & 308 & 8.62 & 8.24 & .74 & .05 \\
\hline Talking with friends & 678 & 8.38 & 8.27 & .66 & .28 \\
\hline Going on trips, outings & 657 & 8.24 & 8.17 & .67 & .75 \\
\hline Job & 397 & 8.02 & 7.79 & .72 & 5.03 \\
\hline Home entertainment & 662 & 7.76 & 7.54 & .62 & .79 \\
\hline Reading books, magazines & 668 & 7.60 & 7.49 & .67 & .31 \\
\hline Going to church & 631 & 7.23 & 7.28 & .66 & $: 17$ \\
\hline Reading newspapers & 675 & 7.17 & 7.10 & .63 & .24 \\
\hline Making things for house & 635 & 6.78 & 6.47 & .57 & .17 \\
\hline Playing sports & 606 & 6.76 & 6.23 & .56 & .12 \\
\hline Going to movies, plays & 629 & 6.65 & 6.38 & .52 & .10 \\
\hline Gardening & 642 & 6.55 & 6.27 & .60 & .15 \\
\hline Cooking & 668 & 6.17 & 6.13 & .60 & .70 \\
\hline Television & 677 & 5.93 & 6.00 & .62 & 2.01 \\
\hline Other shopping & 673 & 5.69 & 5.30 & .57 & .02 \\
\hline Housing repairs and alterations & 635 & 5.11 & 4.94 & .57 & .19 \\
\hline Work, school organizations & 587 & 5.00 & 5.13 & .50 & .27 \\
\hline Grocery shopping & 673 & 4.57 & 4.55 & .56 & .34 \\
\hline Cleaning house & 672 & 4.22 & 4.18 & .57 & 1.13 \\
\hline \multicolumn{6}{|c|}{$\begin{array}{l}\text { Sources: Basic data from luster, "Preferences for Work and Leisure," in Juster and Stafford." } \\
\text { Note: The "reliability" proportion is the fraction of the sample giving the same response to the process benefits } \\
\text { question, plus or minus one scale point, from different surveys taken six months apart in } 1982 \text {. }\end{array}$} \\
\hline
\end{tabular}


activity, measured in hours per day. Not all activities are included (e.g., sleep and personal care are excluded), hence the total time is less than 24 hours. These data provide a number of points of interest.

1. The rank ordering and the quantitative differences among activities indicate considerable stability in the process benefits from activities. There is hardly any change in rank ordering between two periods seven years apart, and the mean values across the population are very similar.

2. The reliability of the data at the level of the individual is quite high. The proportion who gave the same scale response plus or minus one, scparated by a six month span in the 1982 study, range from half the sample to over 80 percent.

3. Activities that are interactive, i.e., that involve other people, tend to dominate the top half of the rankings, while activities that are not interactive or less interactive tend to dominate the bottom half of the rankings.

4. The process benefits associated with paid employment outrank all but a few leisure activities, and clearly have a mean value that is above the mean for leisure activities, the latter weighted by actual time spent in the activity.

5. The process benefits associated with work in the home, with the exception of childcare, tend to rank at the bottom of the list, and clearly have a mean value well below that of paid employment.

The chief surprise in these data is the next-to-last finding-that average process benefits from work outrank average process benefits from leisure. After all, standard utility theory has always argued that it is the combination of income from work (the extrinsic rewards) plus the intrinsic rewards from leisure that go into the utility function, and that the intrinsic rewards from work are negative-people need to be induced to work by the payment of wages, and the function of wages is to overcome the distaste for work. ${ }^{18}$ But these data present quite a different picture. They suggest that the intrinsic rewards from work are, on average, at least as high as the intrinsic rewards from leisure. If that result is taken at face value, it suggests that economists need to do a major rethinking of the elements that go into individual utility functions. ${ }^{19}$

Since that result is counter-intuitive, we designed some methodological tests of the intrinsic satisfaction data in the study conducted in the early 1980s. Basically we took two activities-work for pay in the market, and cleaning the house-and tried to determine whether the responses we were getting could be explained by the respondent's inability to distinguish extrinsic from intrinsic rewards. That is, were the relatively high rankings of work for pay on the process benefits scale a simple consequence of the fact that our respondents were reporting that they liked their jobs because they were well paid? 
The test was to ask respondents, after they had provided scale values for paid work and cleaning the house, why they had made the judgments they had just given us? Specifically, we asked: What is it about your job, or about cleaning the house, that makes you rate it a ? Responses were then coded into various categories, some clearly reflecting extrinsic rather than intrinsic rewards, some equally clearly reflecting intrinsic rewards only.

Statistical tests on the data showed unambiguously that the intrinsic satisfactions reported by respondents as associated with paid employment were not contaminated because respondents mixed up some of the extrinsic rewards with the intrinsic ones. People who gave relatively high scores to paid employment reported that they were thinking about the nonmonetary aspects of the work environment - the people they worked with, the challenge or learning opportunities involved, the amount of supervision and responsibility, whether the job was boring or repetitious, etc. Reference to the financial characteristics of the job did not distinguish respondents who provided relatively high scores from those who provided relatively low scores (Juster ${ }^{(28.29)}$ ).

Interestingly enough, while contamination of the intrinsic satisfaction data with extrinsic reward considerations did not appear to be a factor in interpreting the paid employment responses, it was clearly a major factor in explaining responses to the "cleaning the house" data. When asked why they had provided the ranking they did, the single most important factor for those who provided relatively high rankings was that they "felt good about having a clean house." That is clearly an extrinsic reward, not a process benefit. Adjusting the data for respondents who thus misinterpreted the question dropped the overall population mean score by a full scale point, thus making the gap between the process benefits from paid employment with those from work in the home even larger than shown by the data in the table.

\section{SOME IMPLICATIONS}

Is there any independent evidence suggesting that these results reflect a real phenomenon rather than some kind of socially determined intrinsic satisfaction story derived from a self-report scale? ${ }^{211}$ To begin with, we have already noted that these results do not necessarily negate the proposition that people are willing to trade off work for leisure at the margin. The data clearly relate to average process benefits from particular activities, and do not represent marginal process benefits - the satisfaction obtained from the last minute or hour of a particular activity. Thus, process benefits from work could be very high on average, but could be very low at the margin- 
that would be true if the function drops off very sharply as work hours increase. Thus, the data can be interpreted as saying that many individuals prefer an activity pattern that includes an element of work for pay, not that individuals generally prefer to work longer hours than they now do. The data are thus not inconsistent with the observed long-term decline in work hour and the associated growth in leisure hours.

Moreover, the notion that intrinsic rewards from work are relatively high helps to explain a number of anomalies that represent puzzles for the conventional analysis of utility-maximizing behavior.

- A number of studies have looked at what happens to people who win major prizes in lotteries. (Kaplan ${ }^{(37)}$ ) The typical result is that most people continue to work, often at jobs that contribute only marginally to their total income, taking account of the value of the lottery prize.

- Of the individuals and families eligible for various forms of welfare assistance, a substantial fraction choose not to avail themselves of welfare payments and opt instead to work at jobs that yield total income no better than that obtainable through welfare. Such observations have often been explained on the grounds that people are illinformed, or that they want to avoid the social stigma attached to welfare, or that they are investing in future income by building up labor market experience. But a simpler explanation is that people have a strong preference for work as an activity.

- Over the last 60 or so years, there has been a strong and consistent growth in women's labor force participation, usually explained in economic models as the consequence of the relative growth in market wage rates compared to the value of nonmarket activities. That story has always been unsatisfactory. Labor force participation growth rates have been just as strong in periods when wage rates have been rising slowly or not at all as when wage rates have been rising rapidly, and there has never been any evidence that the gap between productivity in the market and productivity in the home has been increasing. A simpler explanation is that work in the market is associated with significant intrinsic rewards, and quite possibly that these rewards have been shifting upward over time as working wives have become a more socially acceptable phenomenon.

The general proposition advanced here-that the intrinsic rewards from activities are an essential ingredient in individual and household utility functions-has other potentially far-reaching implications for a variety of economic and social phenomenon. For example, it is widely argued that 
many work environments could be more efficiently organized on a cottage industry basis-electronic communication devices make it unnecessary for people to travel to a common work location, and both communication and decision-making processes can conserve on time by creating technically efficient work environments in people's homes. The evidence that interactive activities are more strongly preferred than noninteractive activities makes this vision of the future a dubious one, except for special occasions and special circumstances. Generally speaking, most members of the work force are unlikely to find that type of work environment very satisfactory, since it precludes the kind of interaction that appears to underlie the preference data.

A good many commercial enterprises have adopted the view that serving consumers with technology is a more efficient way to provide a variety of services-banking, shopping, etc. To the extent that preferences for interactive activities are an important phenomenon in the market, those technically more efficient arrangements will not be adopted by a good many consumers if they are only slightly less costly.

While the data suggest that a set of activities that includes work for pay in the market will often be preferred to a set that does not, they certainly do not suggest that people have preferences for an activity package that includes a standard ( 40 hours) work weeks. In fact, the long historic trend of decreasing work hours suggests precisely the opposite, and has usually been interpreted to mean that people prefer leisure to work at the margin of choice. An interpretation consistent with the historical trend, and also with the data and theory discussed above, is that a great many people prefer an activity package which includes some modest amount of paid work, but not necessarily full-time paid work. But the labor market is such that part-time jobs are often hard to find and often regarded by employers as a more costly way to organize work activities. If these preference data are an accurate reflection of true preferences, an employer able to reconfigure work flows to capitalize on the demand for part-time work would be able to attract a productive labor force at relatively modest wage rates, and make a profit by so doing,

\section{SUMMARY}

This reformulation of utility theory in terms of satisfactions derived from activities and those derived from wealth is an insight of considerable potential usefulness. It is simpler and more general than the present formulation, it provides useful insights into behaviors that are difficult to explain with present theory, and it predicts future behaviors that existing theory does 
not. Its weakness, from the viewpoint of traditional theory, is that it relies directly on subjective phenomena that cannot be directly observed, that cannot be traded between participants in a market (except indirectly), and whose implications cannot easily be contradicted by observed behavior. But some of those problems exist also for the current theory of consumer choice, which also cannot easily be contradicted by observed behavior.

Perhaps the best way to assess this theoretical structure is that it provides an accounting framework for describing and measuring well-being, both among individuals and societies, that in principle has great generality and power. The framework involves the measurement of subjective variables, which have never been a great favorite of economists. While variables of this sort contain measurement errors and interpretive ambiguities that are not present in objective variables, that might be better seen as an opportunity and a challenge rather than as a proscription.

\section{NOTES}

1. Juster is Research Scientist, Institute for Social Research, and Professor of Economics, University of Michigan. The research underlying this paper has been supported in part by the National Science Foundation. Grant \#SES-8219275. Helpful comments on the paper were received from Charles Brown, Greg Dow, Roberta Miller, Albert Rees, and Hal Varian. As indicated, this paper draws heavily on previous collaborative work with Paul Courant and Greg Dow.

2. The introductory material in the paper leans heavily on the excellent summaries of the historical development of utility theory provided by Stigler ${ }^{\left({ }^{(65},\left(6 r_{0}\right)\right.}$ and Meeks, ${ }^{(4+)}$ especially the former. A recent $\mathrm{Ph}$.D dissertation by Loewenstein ${ }^{(+2)}$ provides some interesting insights into the intertemporal optimization aspects of utility theory.

The literature on utility theory has been enormous over the years, and includes many of the profession's heavyweights. Nobel prize winners, for example, are prominent among major contributors (Hicks, Arrow, Samuelson, Stigler, Friedman), and if Nobel prizes had been around earlier, Menger, Marshall, Jevons, Pareto, Walras, Slutksy, and Edgeworth would surely have received one.

3. This is technically not quite accurate. Declining marginal utility is a sufficient but not a necessary condition for an optimum solution that involves the consumption of multiple goods rather than only a single good. In the two-good case, the marginal utility of one good can be rising as long as the marginal utility of the other good is falling "rapidly enough," and the optimum combination will still involve consuming some of each good.

4. There are important differences between the conditions for optimality with cardinally measurable utility and ordinally measured preferences. The first has a unique optimum and a true zero point. The second has the much weaker property of being at a maximum point on some utility surface without having to say how much higher than other reachable surfaces it actually is. The first is generally inconsistent with rising marginal utility, while for the second declining marginal utility is neither a necessary nor a sufficient condition for equilibrium. Finally, the first requires strong assumptions about measurability, while the second does not., 
Whether consumers can more plausibly be judged to be able to make the distinctions required by preferences ordering than those required by marginal utility calculations is a different issue. To quote one of the most quotable of the participants, Dennis Robertson (reported in Meeks $\left.{ }^{(+1)}\right)$ commented that:

In slitting the throat of diminishing marginal utility, Hicks and Allen did not leave us destitute: they gave us in its place a creature which every teacher of economics now knows as the marginal rate of substitution. The consumer, it seems, must not go about burdened with the knowledge, or belief, that a little more beef or a little more beer would add so much to his satisfaction; but he may go about with the knowledge, or belief, that he would be ready to go without so much beef for so much extra beer, and likewise for any other two commodities you like to name (Robertson $\left.{ }^{(59)}\right)$.

5. There was not only a good deal of discussion in the literature as to whether the utilities yielded by the consumption of $x_{1} \ldots x_{n}$ were independent of each other, but a more global level, whether the utility of consumer A's consumption bundle is independent of consumer B's consumption (Edgeworth, ${ }^{(15)}$ Mill, ${ }^{1+n)}$ Kaldor, ${ }^{(36)}$ Fisher, ${ }^{(17)}$ Pigou, ${ }^{(5+1)}$ Duesenberry $\left.y^{(13)}\right)$. The general conclusion was that the utilities from consumption are not generally independent, either at the level of an individual consumer's bundle of consumption goods or at the more global level of the total consumption of different individuals, although the latter conclusion is often ignored in the current literature.

6. A plausible reason is that economists tend to think of the labor force as being determined by population characteristics, and work hours as being determined by employers.

7. Of course, wage rates also came to be perceived as a choice variable. One could invest in productivity-related skills by deciding to spend time in school, or by accepting a job with a large training component (Mincer ${ }^{(t+8)}$ ).

8. The literature does contain some suggestion that work activity per se does not necessarily produce negative utility. That is certainly true of the very early discussion in Jevons ${ }^{(20)}$, and can be found in more recent discussions of labor supply (Rees ${ }^{(5)}$ ) In addition, there is substantial literature on compensating wage differentials, which implies that the direct utility from work varies according to job characteristics (Brown, ${ }^{(9)}$ R. S. Smith, ${ }^{(6+)}$ and Duncan \& Holmlund ${ }^{(1+1)}$ ).

9. J. R. Hicks, who was an early enthusiast for preference ordering, thought otherwise in his later writing, seeing marginal utility calculations as closer to what consumers actually do than marginal rate of substitution calculations (Hicks, ${ }^{(2.3)}$ ).

10. This change is usually interpreted (Loewenstein, ${ }^{(12)}$ Meeks ${ }^{(+1)}$ ) as reflecting a desire to depsychologize utility theory on the grounds that the fewer the assumptions the better the theory. Loewenstein interprets it as reflecting increased uneasiness on the part of many economists with the shaky psychological foundations of cardinally measurable utility. Stigler, ${ }^{\left({ }^{(\infty)}\right)}$ notes that many of the big guns in the early development of utility theory (e.g., Pareto, Slutsky) viewed the detaching of the theory from psychological underpinnings as an important simplification.

It is far from clear that consumers think of future consumption as being worth less than an equivalent amount of current consumption. The topic has been much debated in the literature, with a number of writers arguing that future consumption was every bit as valuable as present consumption except for the fact that it was uncertain, and therefore might not take place (e.g., Jevons $\left.{ }^{(26)}\right)$. 
11. A different departure from the goods-leisure model was introduced by Lancaster, who argued that characteristics of products rather than products were what produced utility. Thus consumers were paying for the functions performed by goods, not for the goods themselves (Lancaster ${ }^{(+))}$).

12. This is obviously a gross oversimplification of the development of utility theory. For example, it entirely omits the spirited discussion in the literature about whether individual utility functions could be compared or aggregated (Marshall, ${ }^{(4)}$ Pigou, ${ }^{(5+1)}$ Jevons $\left.{ }^{201}\right)$; whether aggregation of utility functions necessarily yielded consistency in social choices (Arrow, ${ }^{(4)}$ Bergson $^{(7)}$ ) whether any social policy change could be shown to be an improvement in utility terms (Hicks, ${ }^{(21)}$ Arrow, ${ }^{(2.3)}$ Little, ${ }^{(+1)}$ Samuelson, ${ }^{\left({ }^{(1)}\right)}$ Robbins $^{(57)}$ ) and the relation between National Income aggregates and societal well-being (Kuznets, ${ }^{(39)}$ Scitovsky, ${ }^{(62)}$ Nordhaus and Tobin, ${ }^{(51)}$ Griliches, ${ }^{(21)}$ Mishan, ${ }^{(19)}$ Ruggles, ${ }^{(16)}$ Kendrick, ${ }^{(38)}$ Juster, ${ }^{(27)}$ Eisner et al. $\left.{ }^{(16)}\right)$.

In addition, there is the extensive literature concerned with whether consumers maximize expected utility in situations involving risky outcomes. The von NeumannMorgenstern axioms ${ }^{(k+)}$ are the standard view, recently challenged by the prospect theory axioms (consumers are risk-averse when it comes to prospective gains, riskloving when it comes to prospective losses) of Kahneman and Tversky. ${ }^{(35)}$ Friedman and Savage $^{(19)}$ and Arrow $^{(4)}$ are important contributors to this topic.

13. It would be well not to push the latter point too hard-that leisure activities contain only process benefits, and have no extrinsic outcome of value. Many-perhaps mostleisure activities are quite likely to yield some enhancement of a capital stock of one kind or other-health status, the stock of relationships represented by marriage, friendships, etc.

14. A set of production and investment constraints that affect the $Z_{i}$ and $K_{1}$ are also needed in the system.

15. The quote from Fisher not only portends what we have called process benefits, but also clearly foreshadows the notion of the household as a utility producing factory. The utility factory theme, which is more of a return to the Benthamite tradition of focusing on utility flows than an elaboration of the preference ordering notion, reappears in modern form in Stigler and Becker. ${ }^{(67)}$

16. That argument can be found repeatedly in the earlier literature concerned with methods of measuring cardinal utility, e.g., Robbins. ${ }^{(s .8)}$

17. A consistent finding from the Quality of Life studies is that the most important dimensions of satisfaction with one's life as a whole turns out to be noneconomic factors-relationships with family and friends-rather than economic or financial ones.

18. The argument has always been carefully put in marginal terms-the wage rate is needed to overcome the distaste for the last hour of work-and goes back at least to Stanley Jevons.

19. Although the result described here is technically consistent with the traditional theory, it seems unlikely to me that the relevant functions have the necessary shapes. Traditional theory equates the marginal utility of consumption, $U_{c}{ }^{\prime}$, with the marginal utility of leisure, $U_{1}^{\prime}$. The marginal utility of consumption is equal to the marginal utility of income, $U_{y}{ }^{\prime}$, plus the marginal utility of work, $U_{x^{\prime}}{ }^{\prime}$, presumed to be negative in equilibrium. Thus at the point of choice, $U_{i}{ }^{\prime}=U_{c}{ }^{\prime}=U_{y}{ }^{\prime}+U_{w}{ }^{\prime}$, where all the terms except $U_{w}{ }^{\prime}$ are presumed to be positive.

The data indicate that the average utility of $U_{n}{ }^{\prime}$ is higher than the average utility of $U_{1}{ }^{\prime}$. Since the maximum utility yielded by the first minute (or hour) for all possible 
activities is unlikely to be associated with work (there are hundreds of leisure activities, and at least one should represent the maximum), and since leisure activities can be easily substituted for each other as their marginal utility declines, it takes a very peculiar shape for the $U_{w}$ function to get the result that we observe and still maintain the marginal equality conditions shown above. A more plausible interpretation is that disequilibrium often exists, probably because of labor market rigidities on the demand side. For example, the absence of a rich and continuous set of market opportunities to work $5,7.5,10 \ldots$ hours per week at a wage consistent with one's productivity.

20. Quite a lot of analysis has been done using the process benefits data to either describe or model behavior, most of which is reported in Juster and Stafford (Eds.), Time. Goods, and Well-Being. ${ }^{(3)}$ Papers include: Chapter 13, Preferences for Work and Leisure, Juster ${ }^{(24)}$; Chapter 16, Goods, Time, and Well-Being: The Joint Dependence Problem, Greg K. Dow and Juster ${ }^{(2)}$; and Chapter 17, Constraints and Complementarities in Time Use, M. Hill and Juster. ${ }^{(25)}$ In addition, the process benefits data have been examined by Juster in "Changes in Work, Leisure, and Well-Being for Men and Women" (under review), ${ }^{(3)}$ and in "The Distribution of Well-Being among Households" (Juster $\left.{ }^{(2 x)}\right)$.

\section{REFERENCES}

(1) Andrews, F.M., and Withey, S.G. Social Indicators of Well-Being in America. New York: Plenum, 1976.

(2) Arrow, K.J. "A Difficulty in the Concept of Social Welfare," Journal of Political Economy, 58(4) 328-346, 1950.

(3) Arrow, K.J. Social Choice and Individual Values, 2nd ed. New Haven, CT: Yale University Press, 1963.

(4) Arrow, K.J. Essays in the Theory of Risk-Bearing. Chicago: Markham, 1971. (First published under title: Aspects in the Theory of Risk-Bearing. Helsinki, 1965.)

(5) Becker, G.S. "A Theory of the Allocation of Time," Economic Journal, 75:493-517, 1965.

(6) Bentham, J. An Introduction to the Principles of Morals and Legislation. London: Athlone Press, 1970. (Originally published 1789.)

(7) Bergson, A. "A Reformulation of Certain Aspects of Welfare Fconomics." Quarterly Journal of Economics, 52:310-334, 1938.

(8) Bradburn, N.M. The Structure of Psychological Well-Being. Chicago: Aldine Press, 1965.

(9) Brown, C. "Equalizing Differences in the Labor Market," Quarterly Journal of Economics, 94(1):113-134, 1980.

(10) Campbell, A., P. Converse, and W. Rodgers. The Quality of American Life. New York: Russell Sage, 1976.

(11) Cantril, A.H., and C.W. Roll, Jr. Hopes and Fears of the American People. New York: Universe, 1971.

(12) Dow, G.K., and F.T. Juster. "Goods, Time, and Well-Being: The Joint Dependence Problem," in Time, Goods, and Well-Being, edited by F.T. Juster and F.P. Stafford. Ann Arbor: Institute for Social Research, University of Michigan, 1985. 
(13) Duesenberry, J. Income, Savings and the Theory of Consumer Behavior. Cambridge: Harvard University Press, 1952.

(14) Duncan, G.J., and B. Holmlund. "Was Adam Smith Right After All? Another Test of the Theory of Compensating Wage Differentials," Journal of Labor Economics, 1(4): 366-379, 1983.

(15) Edgeworth, F.Y. Mathematical Psychics: An Essay on the Application of Mathematics to the Moral Sciences. New York: Augustus M. Kelley, 1967. (Originally published 1881.)

(16) Eisner, R., E.R. Simons, P.J. Pieper, and S. Bender. "Total Incomes in the United States, 1946-1976: A Summary Report," The Review of Income and Wealth, Series 28(2):133-174, 1982.

(17) Fisher, I. The Theory of Interest. New York: Macmillan, 1930.

(18) Fisher, I. The Nature of Capital and Income. Reprints of Economic Classics. New York: A. M. Kelley, 1965. (Originally published 1906.)

(19) Friedman, M., and L. Savage. "The Utility Analysis of Choices Involving Risk," Journal of Political Economy, 56:279-304, 1948.

(20) Griliches, Z. (Ed.). Price Indexes and Quality Change (Price Statistics Committee, Federal Reserve Board). Cambridge, MA: Harvard University Press, 1971.

(21) Hicks, J.R. "The Valuation of the Social Income," Economica, 7:105-124, 1940.

(22) Hicks, J.R. The Theory of Wages, 2nd ed. New York: St. Martin's Press, 1963.

(23) Hicks, J.R. "Some Questions of Time in Economics," in Evolution, Welfare and Time in Economics: Essays in Honor of Georgescu Roegen, edited by A.M. Tany, F.M. Westfield, and J.S. Worley. Lexington, MA: Lexington Books. 1976.

(24) Hicks, J.R., and R.G.D. Allen. "A Reconsideration of the Theory of Value, Part 1 and Part 2," Economica, 1 (New Series):52-76, 196-219, 1934.

(25) Hill, M.S., and F.I. Juster. "Constraints and Complementarities in Time Use," in Time, Goods, and Well-Being, edited by F.T. Juster and F.P. Stafford. Ann Arbor: Institute for Social Research, University of Michigan, 1985.

(26) Jevons, W.S. The Theory of Political Economy, 4th ed. London: Macmillan, 1911.

(27) Juster, F.T. "A Framework for the Measurement of Economic and Social Performance," in The Measurement of Economic and Social Performance, edited by M. Moss. New York: National Bureau of Economic Research, 1973.

(28) Juster, F.T. "The Distribution of Well-Being among Households," in Bulletin of the International Statistical Institute, 51(1):1.1-1.15, 1985a.

(29) Juster, F.T. "Preferences for Work and Leisure," in Time, Goods, and Well-Being, edited by F.T. Juster and F.P. Stafford. Ann Arbor: Institute for Social Research, University of Michigan, 1985b.

(30) Juster, F.T. "Changes in Work, Leisure, and Well-Being for Men and Women," (under review).

(31) Juster, F.T., P.N. Courant, and G.K. Dow. "A Theoretical Framework for the Measurement of Well-Being," The Review of Income and Wealth, Series 27(1):1-31, $1981 \mathrm{a}$.

(32) Juster, F.T., P.N. Courant, and G.K. Dow. "The Theory and Measurement of WellBeing: A Suggested Framework for Accounting and Analysis." in Social Accounting Systems: Essays on the State of the Art, edited by F.T. Juster and K.C. Land. New York: Academic Press, 1981b. 
(33) Juster, F.T., P.N. Courant, and G.K. Dow. "A Conceptual Framework for the Analysis of Time Allocation Data," in Time, Goods, and Well-Being, edited by F.T. Juster and F.P. Stafford. Ann Arbor: Institute for Social Research, University of Michigan, 1985.

(34) Juster, F.T., and F.P. Stafford (eds.). Time, Goods, and Well-Being. Ann Arbor: Institute for Social Research, University of Michigan, 1985.

(35) Kahneman, D., and A. Trersky. "Prospect Theory: An Analysis of Decision Under Risk," Econometrica, 47:263-291, 1979.

(36) Kaldor, N. "Welfare Propositions of Economics and Interpersonal Comparisons of Utility," Economic Journal, 49:549-552, 1939.

(37) Kaplan, R. "Lottery Winners and Work Commitment," The Journal of the Institute for Socioeconomic Studies, 10(2):82-94, Summer 1985.

(38) Kendrick, J.W. "Expanding Imputed Values in the National Income and Product Accounts," The Review of Income and Wealth Series 25(4):349-363, 1979.

(39) Kuznets, S. National Income and Its Composition, 1919-1938. New York: National Bureau of Economic Research, 1941.

(40) Lancaster, K. "A New Approach to Consumer Theory," Journal of Political Economy 74:132-157, 1966.

(41) Little, I.M.D. A Critique of Welfare Economics, 2nd ed. Oxford: Oxford University Press, 1957.

(42) Loewenstein, G.F. Expectations and Intertemporal Choice. Unpublished Ph.D. Dissertation, Yale University, 1985.

(43) Marshall, A. Principles of Economics, 8th ed. London: Macmillan, 1920.

(44) Meeks, J.G.T. "Utility in Economics: A Survey of the Literature," in Surveying Subjective Phenomena, Volume 2, edited by C.F. Turner and E. Martin. New York: Russell Sage Foundations, 1985.

(45) Michael, R.T., and G.S. Becker. "On the New Theory of Consumer Behavior," Swedish Journal of Economics, 75:378-396, 1973.

(46) Mill, J.S. Utilitarianism (Everyman's Library Edition). New York: Dutton, 1968. (Originally published in 1863.)

(47) Mincer, J. "Market Prices, Opportunity Costs and Income Effects," in C.F. Christ et al., Measurement in Economics: Studies in Mathematical Economics and Econometrics in Memory of Yehuda Grunfeld. Stanford, CA: Stanford University Press, 1963.

(48) Mincer, J. Schooling, Experience, and Earnings. New York: Columbia University Press for NBER, 1974.

(49) Mishan, E.J. The Costs of Economic Growth. New York: Praeger, 1967.

(50) Nerlove, M. "Household and Economy: Toward a New Theory of Population and Economic Growth," Journal of Political Economy, 82(2):S200-S221, 1974.

(51) Nordhaus, W., and J. Tobin. "Is Growth Obsolete?" in Economic Growth (Fiftieth Anniversary Colloquium V). New York: National Bureau of Economic Research, 1972.

(52) Pareto, V. Cours d'Economie Politique. Lausanne: Rouge, 1897.

(53) Pareto, V. Manuel d'Economie Politique, 2nd ed. Paris: Gerard, 1927.

(54) Pigou, A.C. The Economics of Welfare, 4th ed. London: Macmillan, 1932.

(55) Pollack, R.A., and M.L. Wachter. "The Relevance of the Household Production Function and Its Implications for the Allocation of Time," Journal of Political Economy 83:255-277, 1975. 
(56) Rees, A. The Economics of Work and Pay. New York: Harper \& Row. 1973.

(57) Robbins, L. "On the Elasticity of Demand for Income in Terms of Effort," Economica, no. 29, pp. 123-129, June 1930.

(58) Robbins, L. An Essay on the Nature and Significance of Economic Science, 2nd ed. New York: Macmillan, 1935.

(59) Robertson, D.H. Utility and All That. London: Allen \& Unwin, 1952.

(60) Ruggles, R. The Measurement of Economic and Social Performance. Report on National Science Foundation Project SOC 74-21391. New Haven, CT: Yale University, 1978.

(61) Samuelson, P.A. Foundations of Economic Analysis. Cambridge: Harvard University Press, 1948 .

(62) Scitovsky, T. The Joyless Economy: An Inquiry into Human Satisfaction and Consumer Dissatisfaction. New York: Oxford University Press, 1976.

(63) Slutsky, E.E. "Sulla Teoria del Bilancio del Consumatore," Giornale Degli Economisti, Series 3(51):1-26, 1915.

(64) Smith, R.S. "Compensating Wage Differentials and Public Policy: A Review," Industrial and Labor Relations Review, 32:339-352, 1979.

(65) Stigler, G.J. "The Development of Utility Theory I," Journal of Political Economy, 58(4):307-327, 1950a.

(66) Stigler, G.J. "The Development of Utility Theory II," Journal of Political Economy, 58(5):373-396, 1950b.

(67) Stigler, G.J., and G.S. Becker. "De Gustibus Non Est Disputandum," American Economic Review, 67:76-90, 1977.

(68) von Neumann, J., and O. Morgenstern. Theory of Games and Economic Behavior, 2nd ed. Princeton: Princeton University Press, 1947. 